\title{
Research on Location, Functions, and Current Development Situation of Agriculture-related Think Tank
}

\author{
Congping Yin \\ Sichuan Agricultural University, Ya’an, 625014, China \\ 11619152172@qq.com
}

Keywords: Agriculture-related think tank, Location, Function

\begin{abstract}
The research on location, function, and current development situation of agriculture-related think tank has big guidance on completing the building of a moderately prosperous society in all respects and the implementation of great strategy of "Rural Revitalization". The location of agriculture-related think tank includes platform of policy consult, academic research and bidirectional association. The functions of agriculture-related think tank include the policy planning, policy formulation, policy implementation, policy evaluation and talent training. The development of agriculture-related think tanks mainly has the problems of not high development level, lack of overall planning and insufficient innovation mechanism. It can be improved by the development planning, talent introduction and mechanism innovation of agriculture-related think tanks.
\end{abstract}

\section{Introduction}

In recent years, document No. 1 of the Central Committee has put forward a new concept of rural further development, and the Nineteenth National Congress of the Communist Party of China has put forward a great strategic goal of rural revitalization, which has brought new requirements and challenges to rural development. Under this background, the multi-level agricultural think tanks, such as China Rural Development Think Tank Platform and National Agricultural and Rural Development Research Institute, are constantly being established and developed. Now they are in the critical period of building a well-off society in an all-round way. The research on the positioning, functions and development status of agricultural think tanks can not only effectively clarify the platform of agricultural think tanks. Development ideas also play an indispensable role in increasing the vitality of Rural Revitalization.

The agriculture related think tank mainly refers to the research platform for the rural areas and the intellectual support provided for the rural development. It includes not only research institutes set up by the state and governments at all levels for rural development, but also rural research institutes set up by the Academy of Social Sciences and colleges and universities, as well as various organizations set up within the grass-roots society to plan for rural development.

\section{Location of Agriculture-related Think Tank}

\subsection{Platform of Policy Consult.}

The agriculture think tank is the think-tank of the government's rural development. Agricultural think tanks are mainly established to assist the government in decision-making. The scientific degree of division of labor between agricultural think tanks and the government in decision-making process also reflects the level of modernization of the national governance system and governance capacity. Generally speaking, the research of agriculture-related think tanks starts from the public agenda or government commission, and then "experts" carry out analysis and experiments to provide policy recommendations for the government through research reports, lectures or conferences, and form 
alternative schemes. Finally, the government chooses the alternatives and makes decisions in the decision-making process. In this process, agricultural think tanks play an assistant role in decision-making, and are also important "resources" in the decision-making process. The quality of alternatives will directly affect the quality of decision-making. Moreover, the agricultural think tank is a consultative body rather than a policy making organ.

\subsection{Institute of Academic Research.}

The agriculture think tank is an academic research institution. On the one hand, most of the institutions are experts, scholars or experienced people in rural areas. Agricultural think tanks not only provide a platform for communication and exchange, but also form a thinking collision. At the same time, let the professionals in rural areas gather together, which is an important channel to discuss and solve the problems of rural development. For example, the Institute of Rural Revitalization of China Agricultural Investment, which was set up in 2018, gathers well-known experts and scholars from all over the world to discuss rural development issues, which is of great academic significance for solving the problems. On the other hand, most of the existing high-end think tanks for agriculture in China are scientific research institutions, and suggestions for policies are made. It also comes directly from the research results of the subject research and the special research. Through field research, visits and observation, the rural problems are analyzed and studied. Finally, the academic report is formed and the academic behavior is completed.

\subsection{Platform of Bidirectional Association.}

The agriculture-related think tank is the contact platform between the grassroots rural areas and the policy-making organs. On the one hand, think tanks have a detailed understanding of rural areas and can respond quickly to rural conditions. They have a detailed understanding of the actual situation, policy implementation and implementation in rural areas in field visits and surveys, and can timely feedback to decision-making organs and provide appropriate policy recommendations. For example, "China Rural Development Think Tank Platform" of China Rural Research Institute forms five systems which integrate data search, integrated storage, analysis and application. The platform for the development of agriculture-related think tank can dynamically track and observe the rural areas, grasp the real-time situation of the grass-roots rural areas, and have an important influence on government decision-making; on the other hand, it is closely linked with the government. In the platform of agriculture-related think tank, there are not only the direct leadership of government organs, but also the decision makers of government decision-making organs directly involved in the investigation and discussion of agriculture-related think tank. The platform of agriculture-related think tank can accurately and thoroughly understand government decision-making at the first time, and make policy interpretation directly to rural areas to promote policy implementation.

\section{Functions of Agriculture-related Think Tank}

\subsection{Early-warning Policy Planning.}

In the process of rural development, especially in the complicated reform situation, agricultural think tanks should adopt a comprehensive perspective to carry out forward-looking, overall research and policy early warning. They should not only pay attention to the study of rural development trends, choose the right direction and channels of development, but also prevent them from coming out on the basis of development laws or experimental analysis results. Major decision-making errors and deviations.

\subsection{Support Policy Formulation.}

With the comprehensive opening of the Nineteenth National Congress, the great strategy of "revitalizing the countryside" has been put forward, and the countryside has entered a new stage of development. It is not only a rare opportunity but also a severe challenge for the further development 
of the countryside. The government's decision-making is influenced by many factors, as well as the theoretical and data support and policy of agricultural think tanks. It is suggested that there is greater need. Agricultural think tanks should provide policy makers with pertinent and appropriate suggestions based on data or theory to help them formulate policies in view of the urgent problems of rural development.

\subsection{Give Assistance to Policy Implementation.}

On the one hand, agriculture related think tanks should interpret policies and guide public opinion. Firstly, as a participant in policy making, agricultural think tanks interpret in detail the experts in the field of agricultural policy organization issued by the government to increase the public's awareness of the policy; secondly, the promulgation and implementation of government policies will face certain practical obstacles. As an authoritative institution in this field, agricultural think tanks are made up of professionals to rural areas. The hot events are analyzed to guide the development of public opinion and establish public confidence in policy. On the other hand, agricultural think tanks can help policy implementation by increasing public acceptance of policies through direct social counseling services.

\subsection{Evaluate Policy Effectiveness.}

The effectiveness of policy implementation is an important indicator for evaluating policy quality. Agricultural think tanks have a high level of understanding of policies, stronger cognitive ability of policy implementation, solid professional knowledge and resources and conditions for evaluation; secondly, agricultural think tanks have a certain practical basis for rural areas, rich research and understanding of rural areas, and accurate evaluation; lastly, agricultural think tanks are involved in agricultural issues. As a third party, the agricultural think tank has no direct interest, and the policy evaluation is better. Agricultural think tanks participating in policy evaluation can not only have a detailed understanding of the current situation of policy implementation, but also have a guiding significance for the next thinking and research of policy.

\subsection{Talent Training Institution.}

The well-known "revolving door" talent flow mechanism of American think tanks has become a feature of the United States. The identity of think tank members is transformed between government policy makers and research experts. Although China's political system and the development of think tanks are different from that of the United States, the "revolving door" mechanism still exists in our agricultural think tanks. For example, experts and scholars from the Ministry of Agriculture and Rural Areas and the National Development and Reform Commission conducted academic discussions with renowned persons in universities and social fields in the "Forum of Strategic Think Tanks for the Revitalization of Chinese Rural Areas in the New Era", and research experts from some universities held positions in decision-making bodies, which provided a basis for government decision makers. In addition, in order to achieve their own development, agricultural think tanks absorb talents from various aspects of society. They are institutions that train talents from all aspects of society and train research talents for rural development.

\section{Problems of Agriculture-related Think Tank}

\subsection{Development Level Is Not High.}

After the strategy of Rural Revitalization was put forward, agricultural think tanks have developed rapidly, but overall, the development is still limited. For example, from the perspective of agriculture-related think tanks, most of the high-end think tanks are research institutes set up by the state or the government, universities and Social Sciences academies, which have both characteristics. There is a certain degree of decentralization in the focus on rural research, and most of them have just been established in the past two years, and their development is limited. Most of the talents in middle 
and low-end think tanks are "famous teachers, large industrial households, rich and capable persons". There is a big gap between the level of specialization and social division of labor, and there is a lack of talents in law and economy. From the research results, there are still some limitations such as internal communication, and the practical transformation of research results of agricultural think tanks is limited. And some agricultural think tanks are still in the theoretical research of investigation and discovery, and the role of agricultural think tanks is still under further development.

\subsection{Lack of Overall Planning.}

In the past two years, driven by the national policy and the actual situation in rural areas, the development speed of agricultural think tanks in China is obvious to all. However, with the rapid development, the overall planning of agricultural think tanks is still relatively lacking, including the linkage mechanism has not yet been established and perfected, and the single and scattered situation is still obvious. Influencing the information flow of all kinds of agricultural think tanks, resources cannot be shared, and there is a basic overlap in the research. The waste of resources has also become an influential factor in the funding shortage of some agricultural think tanks. The lack of overall planning is the inevitable result of the initial development, and the benefits brought by agricultural think tanks will inevitably be discounted.

\subsection{Insufficient Innovation Mechanism.}

At present, the development of agriculture-related think tanks is still in a potential crisis of institutionalization. For the introduction and flow of talents, incentive mechanism and external communication such as international forums have not yet been established, leading figures and outstanding talents in think tanks are still very scarce, and so on. The mechanism of agricultural think tank is an important factor affecting its development and effectiveness. At present, it is still in the early stage of development. The lack of innovation mechanism will seriously affect the development speed of agricultural think tank.

\section{Development Directions of Agriculture-related Think Tank}

\subsection{To Intensify Development Efforts and Pay Attention to Quality Improvement.}

At the national level and government level, the degree of attention should be further increased. On the one hand, from the breadth system. Through intensifying the development of agricultural think tanks, we will build a system of agricultural think tanks with policy research institutions and consultancy organizations as the main body, universities, scientific research institutes and enterprises as the important support, grass-roots think tanks and social think tanks as the basis of development to meet the requirements of agricultural and rural development; on the other hand, from the depth and quality. Firstly, we should strengthen the introduction and training of talents, maximize the creativity of agricultural think tanks, strengthen the scientific research of agricultural think tanks, and lay a solid intellectual and knowledge foundation for improving the competitiveness of agricultural think tanks. Secondly, we should define the orientation of agricultural think tanks, clarify the development plan, aim at the development goals, pay attention to the scientific development structure of agricultural think tanks, and avoid waste of resources.

\subsection{To overall Manage Agriculture-Related Think Tank and Foster the Concept of System.}

We should speed up the integration of information resources and enhance the level of information management. Through the establishment of a comprehensive information service platform for agricultural think tanks, we can promote the communication of technology, knowledge and data, break down information barriers, and form a platform for data, knowledge and technology sharing of agricultural think tanks with comprehensive coverage and unified utilization in the region. Only when agricultural think tanks develop into interrelated and mutually reinforcing individuals can the modernization of the whole think tank system be improved and its development space be stimulated 
to the maximum extent.

\subsection{Mechanism Innovations on Many Aspects.}

The innovation of institutional mechanism is the source of vitality for the development of agriculture related think tanks. In the direction of research, we should select continuing topics according to long-term goals and scientific strategies, especially the high-end think tanks. The choice of strategic issues is related to the overall development, but the solution of strategic issues is not overnight. There is no doubt about the importance of strategic choice.

In terms of talent utilization mechanism, the development level of talent team and talent structure is an important factor affecting the competitiveness of agricultural think tanks. Because rural research covers a wide range of fields, it is difficult to possess talents in many fields. By increasing the introduction and cultivation, we can improve the scientific and effective talent training system while using but not possessing talents. To alleviate the shortage of outstanding talents, at the same time directly establish and improve the database of agricultural think tanks, and select a group of experts in the field of agriculture with high social visibility as special research fellows of think tanks to provide guidance services for all agricultural think tanks, so as to improve the overall level;

In the research of fund-raising mechanism, funds are the basic conditions for the rapid development of agricultural think tanks, which can ensure the stability of funds by combining financial support and think tank services. While making good use of the national financial research funds, we should give full play to the service advantages of agricultural think tanks in their own fields, provide services to society and enterprises to obtain benefits, and ensure the long-term development of think tanks.

Generally speaking, the construction of think tanks in China is still in the initial stage of development. In the construction of think tanks, agriculture-related think tanks have just emerged in the past two years as "new things", which still need considerable development. However, we can not only focus on the current level of development, nor can we single the standards of western countries as development goals. We should gradually establish a think tank with Chinese characteristics based on the special national conditions and the actual rural conditions of our country and the current development of think tanks concerning agriculture.

\section{References}

[1] Liang Li, Zhang Xuefu. A Visualization-technology-assisted Analysis of the Current Situation and Future Development of the Think Tank Research [J]. Journal of Shenyang Agricultural University (Social Sciences Edition), 2015,17(4): 385-390.

[2] Wang Haiyan, Cao Liying, Shao Xiwu. Research on Education Think-tank Construction of Local Universities in the Era of Big Data [J]. Information Science, 2015, 33(6): 76-80.

[3] Chen Haiyan, Zhu Dan. Discussion about Think Tanks of Agriculture, Rural Development and Farmers [J]. Journal of Anhui Science and Technology University, 2014, 28(2): 81-87.

[4] Ji Chao. How to Build a Characteristic New Think Tank under the Background of Economic Transformation and Development: Based on the Practice of Henan Province's Think Tank of Agriculture, Rural Areas and Peasantry [J]. Think Tank: Theory \& Pracitce, 2016, 1(3): 53-58. 